
\title{
Pengujian Usability Pada Aplikasi Auto Reply For Messenger
Menggunakan SUS
}

\author{
Nasrulloh Isnain ${ }^{1}$, Han Sulaiman ${ }^{2}$, Rahmatika $^{3}$ \\ ${ }^{3 *}$ Universitas Indraprasta PGRI, Jakarta, Indonesia \\ 1nasrullohisnain@gmail.com, ${ }^{2}$ mr.dehans@gmail.com, ${ }^{3}$ rahmatikaunindra@gmail.com
}

\begin{abstract}
Abstrak-Marketplace merupakan perantara penting antara penjual dan pembeli di dunia maya. Situs marketplace merupakan pihak ketiga dalam transaksi online, berbagai jenis marketplace yang sering banyak digunakan salah satunya adalah facebook marketplace. Facebook menyediakan tempat jual dan beli ini dengan tujuan agar para penggunanya bisa dengan mudah mencari dan menemukan berbagai barang menarik yang dijual. Banyak para reseller yang memanfaatkan situs tersebut untuk melakukan transaksi penjualan. Namun ketika kita terjun di dalam penjualan online banyak faktor yang harus di perhatikan salah satunya adalah membalas pesan chat customer. Hal ini sangat penting di dalam dunia penjualan bahkan di tuntut untuk merespon dengan cepat. Permasalahannya adalah terkadang para reseller mempunyai kesibukan selain jualan online sehingga terkadang pesan customer telat respon bahkan tidak terespon. Untuk itu diperlukannya aplikasi Auto Reply For Messenger yang dapat diterapkan pada facebook messenger. Penelitian ini bertujuan untuk mengetahui seberapa efektif dan efisien dalam menangani customer menggunakan Auto Reply For Messenger. Dengan Tahapan tahapan yang diperlukan antara lain analisis kebutuhan, desain, implementasi dan pengujian. Metode pengujian yang diperlukan adalah blackbox dimana pengujian tersebut untuk mengetahui fungsi aplikasi berjalan dengan baik. Sedangkan untuk mengevaluasi kegunaan sistem menggunakan System Usability Scale (SUS). SUS digunakan untuk mengetahui seberapa efektif sistem tersebut digunakan oleh responden. Hasil pengujian SUS berdasarkan kuesioner yang disebar kepada 20 responden dari reseller Brutalists Denim, hasil kuesioner akan didapatkan nilai rata-rata dan akan memiliki penilaian berdasarkan tiga kategori. Dari katergori tersebut menghasilkan nilai rata rata sebesar 81 yang berarti termasuk kedalam kategori acceptable. Berdasarkan hasil tersebut, maka sistem yang dipakai dapat diterima baik dan dapat digunakan serta mampu memberikan kemudahan saat bertransaksi penjualan.
\end{abstract}

Kata Kunci: SUS, Auto Reply For Messenger, Reseller, Marketplace

Abstract- Marketplace is an important intermediary between sellers and buyers in cyberspace. Marketplace sites are third parties in online transactions, various types of marketplaces are often widely used, one of which is the Facebook marketplace. Facebook provides a place to buy and sell with the aim that its users can easily search and find various interesting items for sale. Many resellers use the site to make sales transactions. However, when we engage in online sales, there are many factors that must be considered, one of which is replying to customer chat messages. This is very important in the world of sales even required to respond quickly. The problem is that sometimes resellers have activities other than selling online, so sometimes customer messages are late in responding and even unresponsive. For that we need an Auto Reply For Messenger application that can be applied to facebook messenger. This study aims to determine how effective and efficient it is in handling customers using Auto Reply For Messenger. The necessary stages include needs analysis, design, implementation and testing. The test method needed is blackbox where the test is to find out the application function is running well. Meanwhile, to evaluate the usability of the system using the System Usability Scale (SUS). SUS is used to determine how effectively the system is used by respondents. The results of the SUS test are based on questionnaires distributed to 20 respondents from Brutalists Denim resellers, the results of the questionnaire will get an average value and will have an assessment based on three categories. From these categories, it produces an average value of 81 which means it is included in the acceptable category. Based on these results, the system used is acceptable and can be used and is able to provide convenience when transacting sales.

Keywords: SUS, Auto Reply For Messenger, Reseller, Marketplace

\section{PENDAHULUAN}

Perkembangan teknologi informasi dan komunikasi digital saat ini khususnya internet mengalami perkembangan yang sangat pesat. Dengan berbagai macam kegunaannya, hal ini yang menjadikan internet sebagai kebutuhan pokok bagi sebagian besar orang disamping kebutuhan pangan, sandang, dan papan. Perkembangan internet di Indonesia semakin tinggi, hal ini ditandai dengan adanya peningkatan pengguna internet yang semakin meningkat berpengaruh pada perkembangan e-commerce di Indonesia, khususnya forum jual beli online. Tidak bisa dipungkiri bahwa belanja online menjadi pilihan oleh banyak konsumen untuk memperoleh barang yang diinginkan tanpa menggunakan banyak waktu dan tenaga, adanya kemudahan dalam melakukan transaksi dengan harga cukup bersaing dan kualitas barang yang bagus. Makin berkembangnya teknologi informasi semakin tergesernya media sosial juga digunakan untuk perniagaan.

Aktifitas pengguna internet di Indonesia yang sangat diminati adalah media sosial, cukup banyak media sosial yang berperan penting dalam perniagaan. Penggunaan media sosial disini sangat menguntungkan para pelaku niaga untuk memasarkan produk yang akan dipasarkan, contoh media sosial yang banyak diminati oleh pengguna di Indonesia adalah facebook. Pengguna facebook bukan hanya berperan dalam berinteraksi, tetapi sebagai media untuk berniaga dan memperkenalkan produk yang akan dipasarkan melalui marketplace yang sudah ada di dalam platform facebook itu sendiri. Marketplace adalah tempat untuk melakukan pemasaran produk dan jasa antara penjual dan pembeli menggunakan media internet yang memiliki kedudukan yang sama[1]. Ada juga 
mengatakan marketplace adalah sebuah wadah pemasaran produk secara elektronik yang mempertemukan banyak penjual dan pembeli untuk saling bertransaksi [2]. Sedangkan menurut pendapat yang lain marketplace memiliki konsep seperti pasar tradisional yang seolah-olah berada di internet. Pemilik marketplace berperan sebagai pihak yang memiliki tempat yang dapat mempertemukan antara penjual dengan pembeli pada website mereka[3]. Facebook marketplace adalah tempat untuk melakukan kegiatan jual dan beli yang dikhususkan untuk para pengguna facebook karena marketplace ini berada di dalam platform facebook. Facebook menyediakan tempat jual dan beli ini dengan tujuan agar para penggunanya bisa dengan mudah mencari dan menemukan berbagai barang menarik yang dijual di facebook. Di fitur ini pengguna bisa langsung datang ke marketplace, secara langsung di dalam facebook tanpa harus melakukan download atau install aplikasi lain dan juga dengan menggunakan akun yang sama.

Brutalists Denim adalah konveksi yang bergerak dibidang fashion, memproduksi beberapa produk seperti jaket jeans dan sweater hoodie. Target pasar reseller Brutalist Denim memfokuskan penjualannya pada platform facebook marketplace. Brutalists sendiri memiliki grup yang di dalamnya terdapat banyak reseller yang aktif. Banyak hal yang didiskusikan terkait permasalahan pemasaran, terutama dalam hal membalas pesan pelanggan atau customer. Reseller juga harus memiliki kemampuan antara lain dapat memasarkan produk, contohnya seperti menampilkan gambar produk dengan baik, menulis deskripsi dengan menarik terutama dalam hal berkomunikasi dengan pelanggan. Dalam memasarkan atau mendeskripsikan suatu produk di marketplace terkadang customer masih ingin menanyakan dan mengetahui stok yang ada, untuk menjelaskan hal tersebut, facebook marketplace memanfaatkan facebook messenger untuk berkomunikasi perihal spesfikasi produk dan yang lainnya terhadap penjual. Sering kali pertanyaan atau informasi yang sama dilakukan oleh pembeli terhadap produk yang ingin dibeli, Banyak pesan atau pertanyaan dari pelanggan yang serupa untuk menanyakan suatu produk, hal ini dirasa kurang efisien, karena reseller harus menjawab pertanyaan customer berulang-ulang secara manual. Permasalahan lain adalah customer selalu ingin direspon secara cepat, karena semakin banyaknya chat yang masuk sehingga cutomer yang menunggu mencari atau beralih ke lain. Keterlambatan dalam hal respon bisa berdampak fatal dalam penjualan dan menurunnya peminat pembeli. Untuk itu diperlukan suatu aplikasi yang digunakan untuk merespon pesan secara otomatis yang dapat membantu reseller menjawab pertanyaan dari customer.

Platform framewok pembangun chatbot artificial intelligence berbasis cloud semakin marak. Platform tersebut memungkinkan para developer untuk dapat membangun chatbot tanpa kode atau menggabungkan dengan bahasa pemrograman tertentu. Chatbot merupakan aplikasi layanan yang berinteraksi dengan pengguna melalui percakapan teks. Chatbots ini bisa dipergunakan dalam industri kecil maupun bisnis untuk mengotomatisasi layanan pelanggan sesuai keinginan pengguna yang akan ditangani oleh chatbots sehingga mengurangi kebutuhan tenaga kerja serta pengeluaran [4]. Bot memastikan semua pesan dari pelanggan bisa ditangani dengan cepat. Teknologi chatbot digunakan oleh para pelaku bisnis untuk menyediakan layanan yang aktif selama 24 jam. Hal ini secara tidak langsung akan menjadi nilai tambah yang membuat konsumen lebih menyukai produk yang kita jual dan bisa membuat pelanggan puas akan layanan yang sudah diberikan dengan secara cepat. Salah satu aplikasi dari chatbots adalah Auto Reply For Messenger.

Auto Reply For Messenger adalah sebuah aplikasi yang menerapkan teknologi artificial intelligence yang dapat membantu merespon pesan secara otomatis, seperti welcome message balasan yang dikirim bot pada saat pertama kali jika ada yang mengirim pesan, contain word pesan terkirim apabila pesan yang diterima mengandung kata-kata yang sama dan huruf besar dan kecil tidak berpengaruh, not match pesan yang dikirim ketika pesan yang diterima tidak ada yang sama dengan yang disetting, pattern match bot akan mengecek pola yang lebih spesifik, similiarty match bot akan mengecek tingkat kemiripan pesan yang diterima, start with bot akan memeriksa awal kata pada pesan yang diterima tanpa memperhatikan case sensitive, end with bot akan memeriksa akhir kata pada pesan yang diterima tanpa memperhatikan case sensitive, containing serupa dengan word containing bot akan memeriksa setiap kata yang diterima apabila ada yang sama akan direspon, exact match bot akan memerika kemiripan pesan dan memperhatikan besar kecil huruf jadi harus benar-benar sama, sedangkan all apapun pesan yang diterima bot akan selalu merespon. Aplikasi Auto Reply For Messenger dapat diterapkan pada facebook messenger. Dengan fitur tersebut dapat mengirimkan pesan balasan otomatis kepada siapapun yang mengirimkan pesan ke facebook messenger, sehingga jika ada pembeli yang selalu menginginkan pelayanan yang cepat dan tanggap dapat tertangani dengan maksimal.

\section{METODE PENELITIAN}

\subsection{Tahapan Penelitian}

Tahapan penelitian ini berawal dari menganalisa kebutuhan reseller Brutalist Denim dalam hal membalas pesan pelanggan seacara otomatis dengan menggunakan auto reply chat messenger, selanjutnya mendesain sistem untuk menentukan algoritma yang digunakan pada aplikasi untuk menentukan rule pertanyan pertanyaan yang biasa ditanyakan oleh customer dan diimplementasikan langsung pada facebook messengger kemudian proses perbaikan 
jika terdapat kesalahan dalam rule yang digunakan, setelah dilakukan perbaikan apabila terjadi kesalahan diperlukan tahap evaluasi dan terakhir dilakukan pengujian dengan menggunakan metode black box.

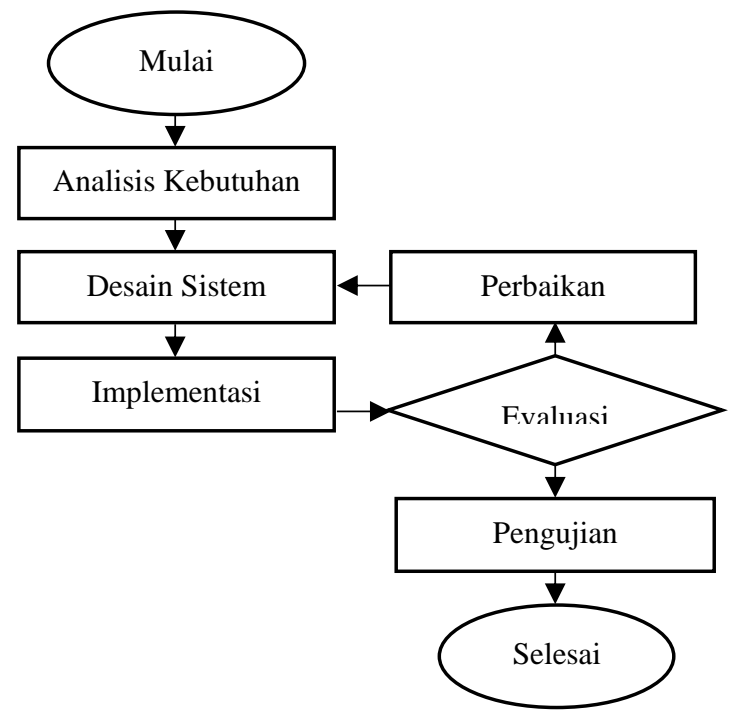

Gambar 1. Diagram tahapan penelitian

\subsection{Analisis Kebutuhan}

Tahap ini diperlukan untuk memahami kebutuhan reseller Brutalist Denim dan sangat penting untuk keberhasilan yang didapatkan. Kebutuhan yang diperlukan mulai dari apa saja pertanyaan yang selalu diajukan oleh customer. Pesan pesan yang selalu diajukan dibagi menjadi beberapa kategori misalnya: welcome messager yang digunakan untuk menjawab pembuka pada chat dan lain sebagainya sesuai kategori katergori yang akan diajukan. Kategori kategori ini yang menentukan pesan apa yang harus dibalas untuk merespon customer dengan benar dan tepat. Adapun messeger yang dibalas memiliki pesan teks yang bisa dipergunakan dalam tahap ini, yakni instant reply berfungsi untuk membalas pesan secara otomatis saat seseorang mengirim pesan. Disini semua pesan otomatis akan direspon serta away message berfungsi untuk membalas pesan saat resseler sedang tidak aktif pada hari tertentu.

\subsection{Desain Sistem}

Aplikasi auto reply for messenger digunakan untuk mempermudah interaksi dengan konsumen. Karena semua pertanyaan konsumen tentang produk, akan dijawab dengan cepat dan otomatis. Sistem ini akan dapat melakukan mengetahui kebutuhan fungsional seperti membalas kalimat pembuka, harga, ongkir, lokasi serta nego harga dan lain sebagainya. Dari kategori kategori mana yang harus dibalas dengan cepat oleh reseller diperlukan algortima untuk menentukan kategori kategori yang benar. Menciptakan rule yang bener menurut algoritma yang digunakan sangat diperlukan dalam mendesain sistem yang ada.

\subsection{Implementasi}

Implementasi diperlukan untuk melihat langkah langkah desain sistem dapat bekerja dengan baik sesuai rule yang ada pada algoritma yang digunakan. Rule bot yang diinginkan bisa mengatur bot, melatih frasa dan respon secara benar dan cepat. Implementasi ini diperlukan untuk melihat seberapa cepat dan respon dari rule pesan yang ada, implementasi ini diperlukan aplikasi facebook messenger untuk menerina pesan dari reseller kepada customer. Gambar 2 hingga gambar 6 merupakan tampilan rule bot yang diperlukan:

Gambar 2 merupakan menu utama langsung tampil menu rule yang pernah dibuat. Gambar 3 terdapat active untuk mengaktifkan dan menonaktifkan aplikasi auto reply, pada reply for messenger app terdapat beberapa pilihan, pilihan pertama FB Messenger akan membalas otomatis bagi pengguna fb standart, pilihan kedua FB Messenger Light akan membalas otomatis bagi pengguna fb light, dan pilihan ketiga Fb Page Manager akan membalas otomatis bagi pengguna page $\mathrm{fb}$. Pilihan Receive message pattern pola pesan yang di terima dari customer Kemudian menentukan algoritma yang di gunakan. 


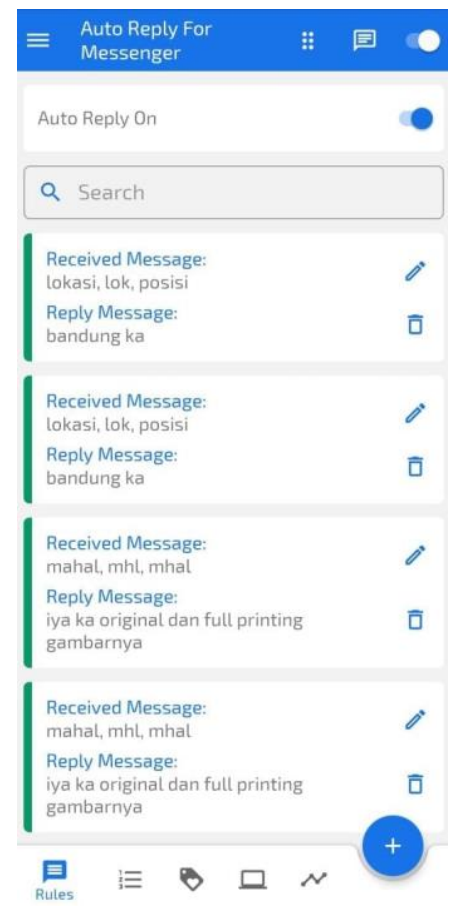

Gambar 2. Menu Utama

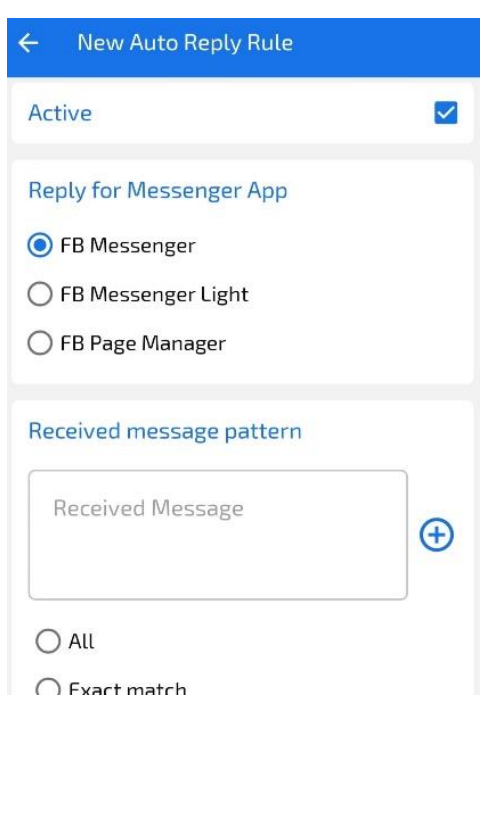

Gambar 3. Menu New Auto Reply Rule

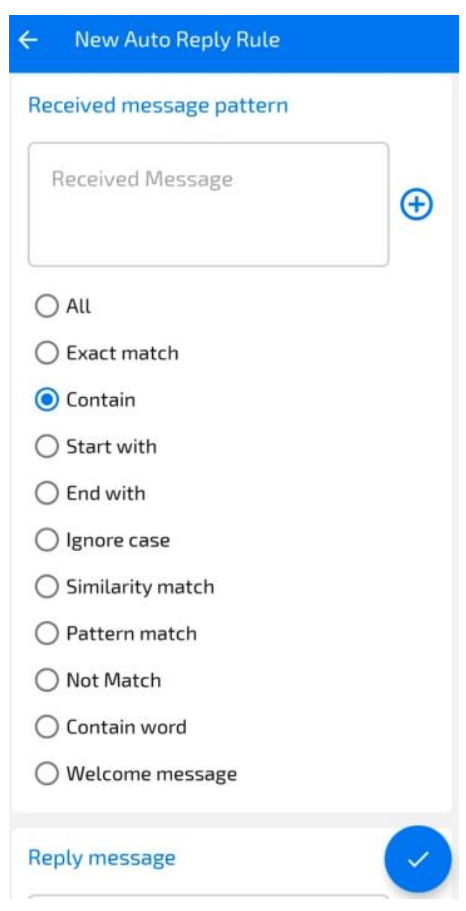

Gambar 4. Rule bot

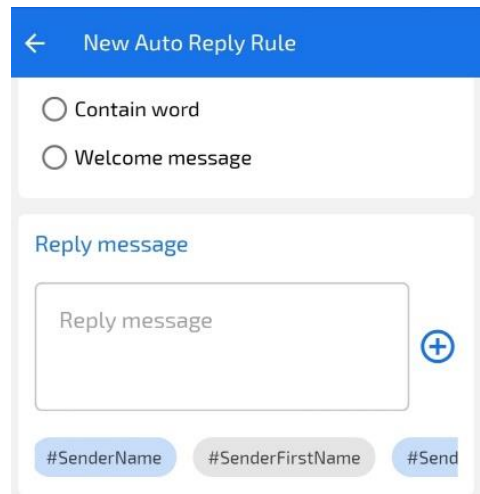

Gambar 5. Reply message

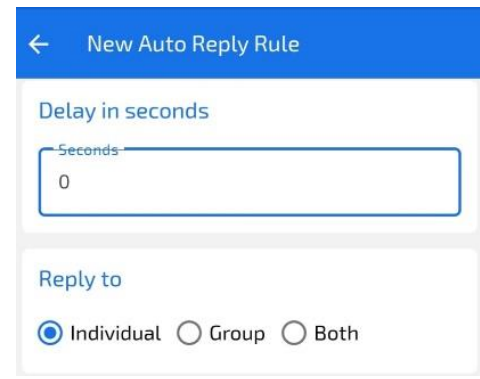

Gambar 6. Delay in second

Gambar 4 untuk memilih algoritma yang diinginkan dalam hal ini tidak semua algoritma digunakan, atau hanya digunakan sesuai kebutuhan saja. Gambar 5. Reply message jawaban pesan yang dikirim sesuai pola pertanyaan customer. Gambar 6. Delay in seconds adalah kecepatan balasan dalam hitungan detik. Pilihan Reply to ada Individual yaitu balasan pesan ke chat pribadi, pilihan Group yaitu balasan pesan ke group marketplace dan pilihan Both yaitu untuk kedua duanya.

\subsection{Pengujian}

Metode pengujian black box digunakan bagi sebagian besar aplikasi yang bisa kita temukan saat ini. Pengujian ini penting untuk menemukan bug atau gangguan pada aplikasi tersebut sebelum dirilis secara resmi. Ada tahapan tahapan yang dilalui oleh blacbox untuk digunakan yakni Functional testing yang diperlukan untuk menguji terhadap fungi atau fitur spesifik. Non Functional testing digunakan untuk menguji pada aspek aspek tambahan non fungsional, Non-functional testing juga melihat apakah software yang telah dirancang dapat dioperasikan dengan baik pada perangkat dan ukuran layar serta sistem operasi yang berbeda-beda. Dan yang terakhir adalah Regression Testing Black box testing tipe ini adalah pengujian yang dapat dilakukan untuk melihat apakah terjadi regresi atau kemunduran ketika versi software di-upgrade. Untuk mengevaluasi nya diperlukan System Usability 
Scale (SUS) Pengujian System Usability Scale dijalankan untuk mengukur aspek-aspek yaitu: efektivitas, efisiensi, dan kepuasan pengguna.

\section{HASIL DAN PEMBAHASAN}

Dalam perkembangan teknologi banyak penilitian yang memanfaatkan chatbot sebagai virtual assistant atau shop assistant[5], [6]. Chatbot adalah salah satu program kecerdasan buatan yang dirancang untuk dapat berkomunikasi langsung dengan manusia dengan bahasa yang sederhana. Chatbot itu sendiri merupakan sebuah sebuah program komputer yang mampu berinteraksi dengan penggunanya dengan bahasa alami[7] Algoritma yang digunakan.Meskipun banyak, bots yang dapat menginterpretasikan dan menanggapi input dari manusia, sebenarnya hanya mengartikan kata kunci ke dalam input dan membalasnya dengan kata kunci yang paling mendekati atau cocok baik pola kata yang paling mirip dari data yang telah ada dalam database yang telah dibuat sebelumnya. Pada saat menggunakan chatbot, pelanggan tidak perlu untuk bertatap muka langsung untuk mendapatkan pelayanan tertentu hal ini membuat pengguna menghemat biaya dan waktu, chatbot juga membuat perubahan ke arah yang lebih baik bagi pelanggan dan perusahaan[8].

Chatbot yang digunakan untuk membalas pesan otomatis adalah Auto Reply For Messenger. Auto Reply For Messenger digunakan untuk membalas pesan otomatis melalui facebook messanger, sebelum penggunaan Auto Reply For Messenger kita harus mengetahui rule-rule yang ingin digunakan dalam auto replay tersebut. Mendesain fitur chatbot perlu dilakukan saat awal dalam membangun chatbot. Pada awal -awal pembuatan diperlukan rule bot, kemudian di integrasikan ke facebook messeger. Rule bot ini digunakan untuk mengkategorikan pesan apa saja yang masuk dan menjawabnya secara otomatis dan benar. Penggunaan rule ini digunakan untuk mengkategorikan pesan yang harus masuk dan diterima oleh customer. Dari katergori yang ada kita dapat membuat pesan otomatis yang memenuhi pertanyaan dari customer dengan baik. Penggunaan rule bot diperlukannya algoritma yang memenuhi standart dari rule bot tersebut. Dari rule yang ada kita dapat mengatur kata atau kalimat. Contoh penggunaan rule bot untuk kategori pada similarity match, jika customer chat yang memiliki kalimat atau pertanyaam yang sama kita bisa atur sesuai kata yang mirip melalui settingan yang kita inginkan. Berikut gambar tampilan similarity match :

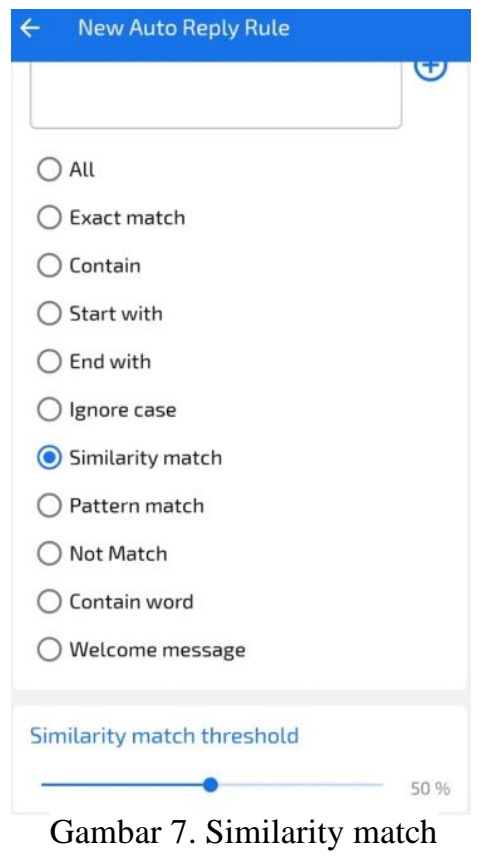

Rule-rule lain yang diperlukan dalam chat bot antara lain : contain, exactly match, word contain word dll. Rule tersebut digunakan untuk kebutuhan fungsional misal, kalimat pembuka, harga, ongkir, ekpedisi,lokasi, info kontak whatsapp dan lain sebagainya yang sering diajukan oleh customer. Dari rule yang sudah ditentukan akan digunakan atau di implementasikan ke facebook messanger, facebook messanger merupakan bagian dari facebook itu sendiri. Berikut Arsitektur facebook messanger bot :

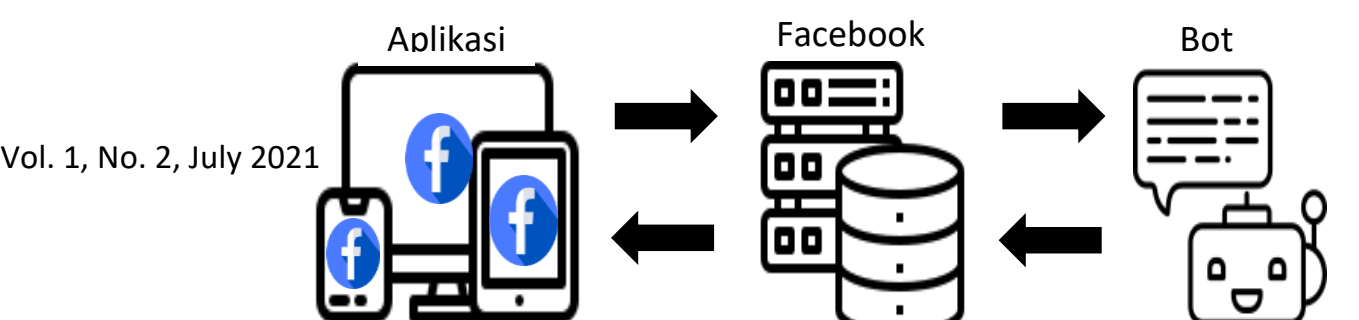




\section{Gambar 8. Arsitektur Facebook Messanger Bot}

Gambar 8. menjelaskan mengenai cara kerja Facebook messanger bot, facebook messanger merupakan aplikasi yang tersedia di dalam aplikasi facebook marketplace, jika customer melihat produk-produk yang di upload pada facebook marketplace, maka customer akan mengirim pesan melalui facebook messanger. Dari pesan tersebut maka, proses pesan disini akan mengirimkan kepada bot, bot akan memproses bedasarkan pilihan dan pesan akan diterima oleh facebook messanger.

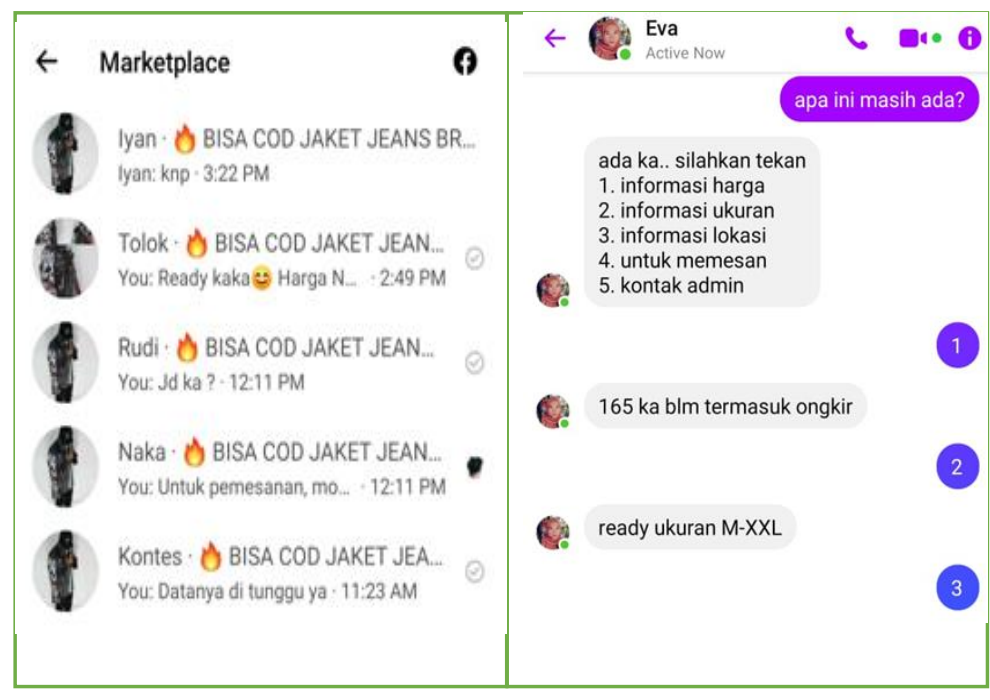

Gambar 9. (a) (b)

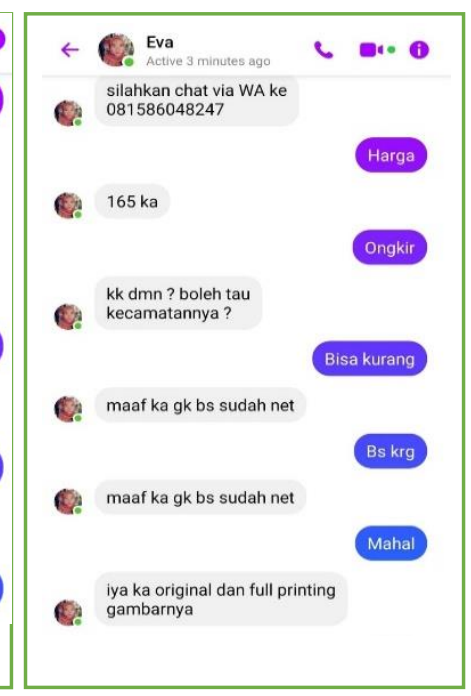

(c)

Gambar 9. (a) Gambar Kalimat Pembuka Welcome Message sebagai balasan kalimat pembuka saat pertama kali customer kirim pesan dan pesan akan otomatis dikirim sesuai pesan yang telah kita buat terlebih di rule bot, (b) Gambar Algoritma Exactly Match Bot bekerja apabila pesan sesuai dengan pilihan yang ada yang telah ditentukan oleh customer maka akan dijawab sesuai yang ditentukan, dan (c) Gambar Algoritma Containing Word bot bekerja apabila pesan dari customer memiliki kalimat yang sama atau mirip, sehingga pesan akan ditampilkan otomatis sesuai kata-kata yang dianggap mirip.

\subsection{Pembahasan}

Tahapan ini adalah tahapan pengujian dan evalusi sistem, metode yang digunakan adalah blackbox testing untuk menguji fungsional sistem. Blackbox testing digunakan unruk menguji rule-rule dalam chatbot. Teknik-teknik Black-box Testing yang diperlukan antara lain :

a. Equivalence Partitionin Cara kerja teknik ini adalah dengan melakukan partition atau pembagian menjadi beberapa partisi dari input data.

b. Boundary Value Analysis Teknik ini lebih fokus kepada boundary, adakah error dari luar atau sisi dalam software, minimum, maupun maksimum nilai dari error yang didapat.

c. Fuzzing Fuzz merupakan teknik untuk mencari bug atau gangguan dari software dengan menggunakan injeksi data yang terbilang cacat ataupun sesi semi-otomatis.

d. Cause-Effect Graph Ini adalah teknik testing dimana menggunakan graphic sebagai acuannya. Dimana dalam grafik ini menggambarkan relasi antara efek dan penyebab dari error tersebut.

e. Orthogonal Array Testing Dapat digunakan jika input domain yang relatif terbilang kecil ukurannya, tetapi cukup berat untuk digunakan dalam skala besar. 
f. All Pair Testing Dalam teknik ini, semua pasangan dari test case di desain sedemikian rupa agar dapat dieksekusi semua kemungkinan kombinasi diskrit dari seluruh pasangan berdasar input parameternya. Tujuannya testing ini adalah memiliki pasangan test case yang mencakup semua pasangan tersebut.

g. State Transition Testing ini berguna untuk melakukan pengetesan terhadap kondisi dari mesin dan navigasi dari user interface dalam bentuk grafik.

Tabel 1 merupakan hasil pengujian dengan menggunakan metode blacbox. Pengujian digunakan pada rule rule bot untuk mengirim pesan otomatis kepada customer. Rule rule bot ini yang akan mengatur autoreplaymessanger. Dari hasil yang didapatkan untuk blackbox testing tidak ada kendala yang signifikan dalam penggunaannya, dan rule rule bot berhasil dijalankan dan di terapkan di facebook messanger.

Tabel 1. Blackbox Testing

\begin{tabular}{|c|c|c|c|}
\hline BOT & Test Case & Hasil yang diharapkan & Hasil \\
\hline All & $\begin{array}{l}\text { Apapun pesan yang diterima bot akan selalu } \\
\text { merespon }\end{array}$ & Berhasil merespon pesan & Valid \\
\hline Exact Match & $\begin{array}{l}\text { Bot akan memeriksa kemiripan pesan dan } \\
\text { memperhatikan besar kecil huruf }\end{array}$ & $\begin{array}{l}\text { Berhasil memeriksa } \\
\text { tingkat kemiripan pesan }\end{array}$ & Valid \\
\hline Contain & $\begin{array}{l}\text { Bot akan memeriksa setiap kata yang diterima } \\
\text { apabila ada pesan yang sama akan direspon }\end{array}$ & $\begin{array}{l}\text { Berhasil memeriksa } \\
\text { pesan yang sama }\end{array}$ & Valid \\
\hline Start With & $\begin{array}{l}\text { Bot akan memeriksa awal kata pada pesan yang } \\
\text { diterima tanpa memperhatikan case sensitive }\end{array}$ & $\begin{array}{l}\text { Berhasil memeriksa } \\
\text { pesan pertama masuk }\end{array}$ & Valid \\
\hline End With & $\begin{array}{l}\text { Bot akan memeriksa akhir kata pada pesan yang } \\
\text { diterima tanpa memperhatika case sensitive }\end{array}$ & $\begin{array}{l}\text { Berhasil memeriksa } \\
\text { pesan terakhir pada pesan }\end{array}$ & Valid \\
\hline $\begin{array}{l}\text { Similarity } \\
\text { Match }\end{array}$ & $\begin{array}{l}\text { Bot akan mengecek tingkat kemiripan pesan yang } \\
\text { diterima }\end{array}$ & $\begin{array}{l}\text { Berhasil mengirim pesan } \\
\text { jika terdapat pesan yang } \\
\text { sama }\end{array}$ & Valid \\
\hline Pattern Match & Bot akan mengecek pola yang lebih spesifik & Berhasil mengecek pola & Valid \\
\hline Not Match & $\begin{array}{l}\text { Pesan akan dikirim ketika pesan yang diterima } \\
\text { tidak ada yang sama dengan yang di set }\end{array}$ & $\begin{array}{l}\text { Berhasil mengirim pesan } \\
\text { jika tidak ada set yang } \\
\text { dipilih }\end{array}$ & Valid \\
\hline Contain Word & $\begin{array}{l}\text { Pesan terkirim apabila terdapat pesan yang } \\
\text { mengandug kata kata yang sama }\end{array}$ & $\begin{array}{l}\text { Berhasil mengirim pesan } \\
\text { yang mengandung kata } \\
\text { yang sama }\end{array}$ & Valid \\
\hline $\begin{array}{l}\text { Welcome } \\
\text { Message }\end{array}$ & $\begin{array}{l}\text { Mengirim pesan balasan yang dikirim bot saat ada } \\
\text { pesan pertama masuk }\end{array}$ & $\begin{array}{l}\text { Berhasil mengirim pesan } \\
\text { balasan saat pesan } \\
\text { pertama masuk }\end{array}$ & Valid \\
\hline
\end{tabular}

\subsection{Hasil Analisis Kemanfaatan}

System Usability Scale (SUS) merupakan salah satu metode uji pengguna yang didalamnya menyediakan alat ukur yang dapat diandalkan. Metode uji pengguna ini diperkenalkan oleh John Brooke pada tahun 1986 yang dapat dimanfaatkan untuk melakukan evaluasi dari berbagai jenis produk ataupun layanan, termasuk di dalamnya hardware, software, perangkat mobile, website, maupun aplikasi lainnya[9]. System Usability Scale (SUS) untuk menentukan respondennya tidak memiliki konsep yang baku, kondisi tersebut disebabkan responden dari System Usability Scale (SUS) pengguna akhir dari produk perangkat lunak yang dapat melakukan evaluasi maupun pengujian. Dalam beberapa kajian menunjukkan System Usability Scale (SUS) menggunakan responden yang berbeda bahkan sampai dengan empat ratus sembilan puluh sembilan responden[10]. System Usability Scale (SUS) ini merupakan skala usability yang handal, populer, efektif dan murah. Daftar Pertanyan SUS memiliki 10 pertanyaan dan 5 pilihan jawaban. Pilihan jawaban terdiri dari sangat tidak setuju sampai sangat setuju. SUS memiliki skor minimal 0 dan skor maksimal 100. Kinerja kuesioner berdasarkan skala usability yang ditampilkan di Tabel 2. Kuesioner tersebut akan diajukan kepada reseller Brutalists Denim, kuesioner atau pertanyanpertanyaan tersebut akan dijawab oleh reseller berdasarkan penggunaan sistem yang telah digunakan. Kuesioner tersebut melibatkan 20 responden. Dari pertanyaan tersebut terdapat skor yang diperlukan yakni dari satu sampai lima untuk menguji skor tersebut dalam perhitungan akhir System Usability Scale (SUS). Pertanyan-pertanyan diajukan untuk mengetahui seberapa besar sistem ini mampu digunakan oleh reseller dan apakah terdapat kendala dalam penggunaannya dan apakah diperlukan evaluasi atau bantuan ahli dalam penggunaannya. 
Tabel 2. Pertanyaan Kuesioner System Usability Scale (SUS)

\begin{tabular}{|l|l|l|}
\hline No & \multicolumn{1}{|c|}{ Pertanyaan } & Poin \\
\hline 1 & Saya berpikir akan menggunakan sistem ini lagi & $1-5$ \\
\hline 2 & Saya merasa sistem ini rumit untuk digunakan & $1-5$ \\
\hline 3 & Saya merasa sistem ini mudah digunakan & $1-5$ \\
\hline 4 & Saya membutuhkan bantuan dari orang lain atau teknisi dalam menggunakan sistem ini & $1-5$ \\
\hline 5 & Saya merasa fitur-fitur sistem ini berjalan dengan semestinya & $1-5$ \\
\hline 6 & Saya merasa ada banyak hal yang tidak konsisten (tidak serasi pada sistem ini) & $1-5$ \\
\hline 7 & Saya merasa orang lain akan memahami cara menggunakan sistem ini dengan cepat & $1-5$ \\
\hline 8 & Saya merasa sistem ini membingungkan & $1-5$ \\
\hline 9 & Saya merasa tidak ada hambatan dalam menggunakan sistem ini & $1-5$ \\
\hline 10 & Saya perlu membiasakan diri terlebih dahulu sebelum menggunakan sistem ini & $1-5$ \\
\hline
\end{tabular}

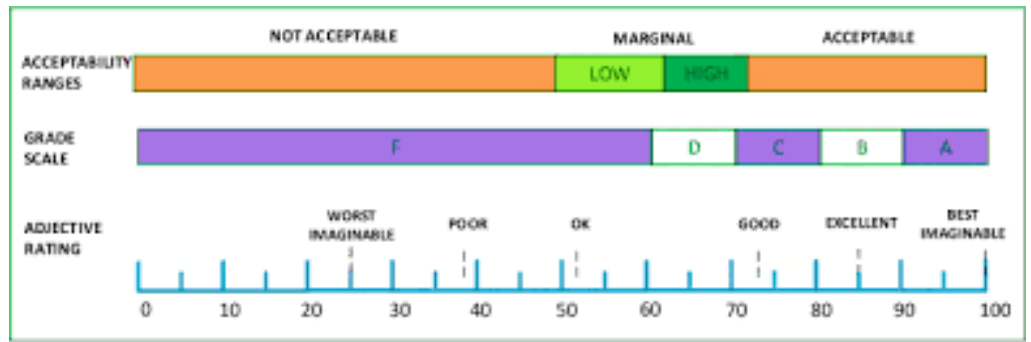

Gambar 10. Skor System Usability Scale (SUS)

Gambar 10 merupakan skor perhitungan Kuesioner System Usability Scale (SUS) menggunakan 5 poin skala Likert. Reseller diminta untuk memberikan penilaian "Sangat tidak setuju", "Tidak setuju", "Netral", Setuju”, dan "Sangat setuju" atas 10 item pernyataan System Usability Scale (SUS) sesuai dengan penilaian subyektifnya. Jika responden merasa tidak menemukan skala respon yang tepat, responden harus mengisi titik tengah skala pengujian. Setiap item pernyataan memiliki skor kontribusi. Setiap skor kontribusi item akan berkisar antara 0 hingga 4 . Untuk item 1,3,5,7, dan 9 skor kontribusinya adalah posisi skala dikurangi 1. Untuk item 2,4,6,8, dan 10, skor kontribusinya adalah 5 dikurangi posisi skala. Kalikan jumlah skor kontribusi dengan 2.5 untuk mendapatkan nilai keseluruhan system usability. Skor System Usability Scale (SUS) berkisar dari 0 hingga 100. Berikut rumus perhitungan skor System Usability Scale (SUS):

Skor SUS $=((R 1-1)+(5-R 2)+(R 3-1)+(5-R 4)+(R 5-1)+(5-R 6)+(R 7-1)+(5-R 8)+(R 9-1)+$ $(5-R 10)) * 2.5)$

Skor SUS keseluruhan diperoleh dari rata-rata skor SUS individual.

Setelah menyebar kuesioner ke reseller dan dilakukan perhitungan SUS, maka akan ditemukan hasil akhir atau skor rata-rata, dimana Skor SUS dapat menunjukkan tingkat penerimaan pengguna. Skor SUS harus bernilai lebih dari 70 [11] agar termasuk ke dalam kategori Acceptable.

Tabel 3 Hasil Penilaian Responden berdasarkan System Usability Scale (SUS)

\begin{tabular}{c|c|c}
\hline Responden & Hasil Penilaian & Skor \\
\hline 1 & $38 \times 2.5$ & 95 \\
2 & $30 \times 2.5$ & 75 \\
3 & $30 \times 2.5$ & 75 \\
4 & $33 \times 2.5$ & 83 \\
5 & $30 \times 2.5$ & 75 \\
6 & $35 \times 2.5$ & 88 \\
7 & $31 \times 2.5$ & 78 \\
8 & $32 \times 2.5$ & 80 \\
9 & $31 \times 2.5$ & 78 \\
10 & $28 \times 2.5$ & 70 \\
11 & $30 \times 2.5$ & 75 \\
12 & $29 \times 2.5$ & 73 \\
13 & $39 \times 2.5$ & 98 \\
14 & $32 \times 2.5$ & 80 \\
\hline
\end{tabular}




\begin{tabular}{l|c|c}
\hline 15 & $31 \times 2.5$ & 78 \\
16 & $37 \times 2.5$ & 93 \\
17 & $32 \times 2.5$ & 80 \\
18 & $35 \times 2.5$ & 88 \\
19 & $29 \times 2.5$ & 73 \\
20 & $32 \times 2.5$ & 80 \\
\hline
\end{tabular}

Perhitungan nilai rata-rata menggunakan persamaan berikut [12]:

Nilai rata rata $=\sum_{i=1}^{n} x i / N$

dimana: xi : nilai score responden

$\mathrm{N}$ : Jumlah Responden

Penilaian berdasarkan 3 (tiga) kategori:

a. Not Acceptable $=$ skor 0-50,9

b. Marginal = skor 51-70,9

c. Acceptable $=$ skor $71-100$

Tabel 3 Merupakan hasil perhitungan akhir dari System Usability Scale (SUS) yang bernilai rata rata adalah 81 yang berarti tergolong ke dalam kelompok acceptable. Berdasarkan hasil tersebut, maka sistem yang dipakai dapat diterima baik dan dapat digunakan oleh reseller tanpa melakukan perbaikan dan dapat mampu memberikan kemudahan saat transaksi penjualan di facebook marketplace.

\section{KESIMPULAN}

Auto Reply For Messenger digunakan untuk memenuhi kebutuhan reseller dalam menjawab pesan otomatis di dalam facebook messanger yang di gunakan untuk meningkatkan penjualan di Brutalists Denim. Sistem ini perlu adanya rule rule dipakai sehingga jawaban dari pesan tersebut memenuhi kriteria yang ditanyakan oleh customer. Dari rule bot tersebut, bot akan memilah milah kata atau kalimat yang diperlukan, bot tersebut akan mengirin pesan ke facebook messanger melalui Auto Reply For Messanger. Sistem ini telah melewati beberapa tahap pengujian, yaitu menggunakan metode blackbox testing melalui kuesioner dengan hasil sistem dapat berjalan sesuai dengan fungsinya. Kemudian kuesioner tersebut dilakukan pengujian System Usability (SUS) yang melibatkan 20 orang responden resseller dari di Brutalists Denim, perhitungan skor SUS ini digunakan untuk mendapatkan hasil akhir atau hasil dari rata yang mendapatkan nilai akhir 81, yang dapat disimpulkan bahwa user atau reseller menyetujui untuk mengimplementasikan sistem ini. Dari hasil perhitungan akhir SUS dapat dikatergorikan sebagai acceptable yang artinya sistem ini bisa dipergunakan dan dapat diterima baik oleh reseller tanpa melakukan perbaikan dan dapat mampu memberikan kemudahan saat transaksi penjualan di facebook marketplace. Penelitian ini nantinya dapat dikembangkan lagi dengan menambahkan rule rule bot dan fungsi serta kriteria kriteria yang baru salah satunya adalah fitur pengiriman, produk dll.

\section{REFERENCES}

[1] J. Sundari and E. R. Nainggolan, "E-Marketplace Desa Gerabah Untuk Pengrajin Di Desa Bumi Jaya Serang Banten,” J. Ind. Serv. Vol. 3 No. la Oktober 2017, vol. 3, no. 1, pp. 68-73, 2017.

[2] A. Y. S. Deni Apriadia, "Lumbar spinal stenosis treated with polyetheretherketone pedicle screw fixation combined with interbody fusion: A follow-up assessment focusing on bone fusion rate," RESTI (Rekayasa(Rekayasa Sist. dan Teknol. Informasi), vol. 1, no. 2, pp. 131-136, 2017, [Online]. Available:

https://jurnal.iaii.or.id/index.php/RESTI/article/view/36/20.

[3] T. P. Artaya, Putu, "Efektifitas Marketplace Dalam Meningkatkan Konsentrasi," J. Ekon. Dan Bisnis, Univ. Narotama Surabaya, no. April, pp. 1-10, 2019, doi: 10.13140/RG.2.2.10157.95206.

[4] H. P. and N. M. R. Singh, M. Paste, N. Shinde, "Chatbot using TensorFlow for small Businesses," Int. Conf. Inven. Commun. Comput. Technol., pp. 1614-1619, 2018, [Online]. Available: https://ieeexplore.iee.org/document/8472998.

[5] A. Bayan, "Chatbots: Are They Really Useful?," LDV-Forum, 2007.

[6] M. Eduardo, "Inttelligent Web Navigation Using Virtual Assistant," Univ. Granada, 2007.

[7] C. Macrae, Learning Form Jquery. Boston: Addison Wesley, 2013. 
[8] Nguyen M-H, "From Fortune 500s to small businesses, real businesses are already using chatbots to improve their service," 2017. .

[9] N. Thomas, "How to use the system usability scale ( SUS ) to evaluate the usability of your website," Usability Geek, 2015. http://usabilitygeek.com/how-to-use-the-system-usability-scale-sus-to-evaluate-the-usability-of-yourwebsite/ (accessed Jun. 01, 2021).

[10] T. Kortum, P and B. A, "No TiUsability ratings for everyday products measured with the System Usability Scaletle," Int. J. Hum. Comput. Interact., vol. 29, pp. 67-76, 2013.

[11] J. Brooke, “SUS: A Retrospective,” J. Usability Stud., vol. 8, no. 2, pp. 29-40, 2013, [Online]. Available: https://www.researchgate.net/profile/John-Brooke-

6/publication/285811057_SUS_a_retrospective/links/5ee5c4a792851ce9e7e38a75/SUS-a-retrospective.pdf.

[12] H. Rachmi and S. Nuwahyuni, "Pengujian Usability Lokamedia Website Menggunakan System Usability Scale," AL-KHIDMAH, vol. 1, no. 2, pp. 86-92, 2018, doi: 10.1201/9781315274508-20. 